\title{
LETRAMENTO LITERÁRIO E AVALIAÇÃO: EMPALHANDO A BORBOLETA?
}

\author{
Literary Literacy and Assessment: stuffing the butterfly?
}

Vera Helena Gomes WIELEWICKI - UEM

RESUMO: Este trabalho discute o conceito de letramento literário como proposto por Zappone (2007) e o ensino de literaturas de língua inglesa no Brasil. Tendo em vista a preocupação do letramento literário com os contextos sociais em que esses textos são produzidos, circulam e são recebidos, discutem-se as implicações dessa abordagem para o ensino de línguas estrangeiras em ambientes escolarizados e, consequentemente, para a formação de professores. Como desdobramento dessa questão, discute-se o papel da avaliação na educação institucionalizada, em contextos de letramento literário.

PALAVRAS-CHAVE: letramento literário; avaliação; literaturas de língua inglesa; formação de professores; ensino de língua inglesa.

\begin{abstract}
This paper aims at discussing the concept of literary literacy (Zappone 2007) and the teaching of literatures in English in Brazil. Starting from the concern of the literary literacy with the social contexts in which such texts are produced, circulate and are received, the implications of such approach for the teaching of foreign languages in institutionalized environments are discussed. Consequently, teacher education is also taken into account here. Following the discussion, the process of testing the students at schools, and its implications for the contexts of literary literacy is reviewed.
\end{abstract}

KEY-WORDS: literary literacy; testing; literatures in English; teacher education; English teaching.

A preocupação com a literatura e o ensino de línguas não parece ser exclusividade dos professores de literatura. Contar com o apoio da literatura para o ensino de línguas, em especial estrangeiras, apresenta-se como uma possibilidade válida. Essa perspectiva, entretanto, nem sempre é contemplada pelos currículos de cursos de licenciaturas em Letras, cujo propósito é formar professores de línguas. A literatura estrangeira, nesse contexto, encontra-se em situação bastante delicada, já que não se apresenta de forma direta nos currículos do ensino fundamental ou médio da educação brasileira. Dessa forma, o trabalho com as licenciaturas em cursos de Letras deriva de uma tradição descontextualizada da prática pedagógica futura dos professores em formação, calcada em conhecimentos baseados em informações sobre o cânone literário, em especial da Inglaterra e Estados Unidos. Ao mesmo tempo, reformulações dos currículos dos cursos de licenciaturas vêm levando a uma reflexão mais aprofundada sobre a formação do profissional do ensino e a proposta de componentes curriculares desses cursos passa a visar de forma mais específica a formação do 
professor. Desde 2002, com as Resoluções do Ministério da Educação (CNE/CP 1 e 2) acerca dos cursos de licenciaturas, uma perspectiva diferente sobre as disciplinas ofertadas por esses cursos passa a ser debatida, entendendo-se que seus componentes curriculares devem contemplar a prática. Orientação ainda bastante polêmica (CALVO e FREITAS 2011), a prática como componente curricular é entendida por muitos como a reflexão acerca da prática pedagógica do professor em formação. Desta perspectiva, a dimensão prática da literatura estrangeira leva, necessariamente, a uma revisão da postura bacharelesca que vinha sendo adotada. Não é, definitivamente, a literatura estrangeira dos bacharéis que teria aplicações na prática pedagógica de professores de línguas. Assim, é necessário, também, rever as relações entre literatura e seu ensino na universidade. Estudar apenas história, teoria e crítica literárias não parece mais suficiente para responder às necessidades do futuro professor. É assim que teorias que procuram dar conta do envolvimento do aluno com a produção significativa de conhecimento e seu impacto social vêm se juntar às tradicionais formas de estudar e ensinar literatura, como o letramento literário. A avaliação, nesse contexto, também precisa ser revista, já que não se pode mais avaliar se o professor em formação estará apto para ensinar literatura apenas com a testagem de seus conhecimentos de história, teoria e crítica literárias. Da mesma forma, as maneiras de se avaliar os conteúdos ensinados e testados pela escola de ensino fundamental e médio precisam passar por uma reconcepção. Assim, o objetivo deste trabalho é discutir o letramento literário como uma possibilidade de abordagem da literatura estrangeira na formação de professores de língua e suas implicações para a avaliação.

\section{LETRAMENTO LITERÁRIO}

As teorias de letramento preocupam-se com as práticas cotidianas e sua significação para a construção de sentidos dos indivíduos. Assim é que o conjunto de saberes necessários para a inserção das pessoas nas comunidades em que vivem, em suas diferentes esferas, e suas possibilidades de atuarem diretamente sobre esses saberes, é objeto dos estudos dos letramentos. Interessa investigar, por exemplo, como as pessoas se relacionam com os diferentes discursos presentes no seu cotidiano, como o discurso político, das propagandas, funcional (instruções de como preencher um formulário, por exemplo). Aqui, não apenas os discursos escritos interessam. A linguagem corporal corrobora ou ironiza a fala; os sons trazem significados, bem como as cores. Contemporaneamente, a linguagem virtual está presente nas vidas das pessoas a tal ponto que o indivíduo que não consegue minimamente relacionar-se com ela será rotulado como iletrado digital. Nesse contexto, pergunta-se 
se a literatura pode ser considerada um desses saberes cotidianos com os quais as pessoas se relacionam. Seria possível afirmar que a literatura ${ }^{1}$ constitua uma forma de saber com suas práticas específicas e que tenha impacto nas vidas das pessoas a ponto de interferir socialmente e, assim, justificar uma prática pedagógica que trate de suas relações com uma produção, circulação e recepção desse saber?

Para alguns estudiosos, sim. Zappone (2007) deriva de Kleiman (2004) e Rojo (2006) as preocupações com os efeitos da leitura e escrita nos indivíduos e o papel da escola nesse processo. Para Kleiman (2004), a escola normalmente não se preocupa com os sentidos das práticas cotidianas que utilizam a escrita. Rojo (2006) aponta para a multiplicidade de escritos no cotidiano e suas relações com multiplicidades também de formas orais. Os alunos, entretanto, estariam mais familiarizados com formas textuais orais do que escritas. Zappone (2007) busca em Street (1984) discussões sobre diferentes práticas de letramento, observadas fora da escola, como em diversos contextos com a família, em comunidades religiosas, no trabalho, atividades ligadas ao lazer, etc. Consequências da cultura e das estruturas de poder de uma sociedade, as práticas de letramento mudam em diferentes contextos sociais. Para Street, tais práticas constituem o modelo ideológico de letramento, pois a escrita assume diferentes significados dependendo dos contextos sociais. O letramento desenvolvido na escola, entretanto, chamado de modelo autônomo, vê a escrita como um produto completo em si mesmo, e busca seu significado no próprio texto, em suas partes constitutivas, em seu funcionamento lógico. No modo autônomo de letramento, as atividades desenvolvidas com a escrita são feitas com base no texto e seu significado está aí presente.

Compreendendo literatura a partir da ficcionalidade, que se opera em diferentes formas de configuração mimética (dramática, lírica, narrativa, épica), Zappone (2007) propõe, então, que o conceito de letramento possa ser produtivo para o entendimento de alguns aspectos acerca da produção, recepção e circulação da literatura, bem como de seu ensino. Zappone (2007) aponta quatro pontos que poderiam nortear uma compreensão de letramento literário. Primeiro, o letramento literário "pode ser compreendido como o conjunto de práticas sociais que usam a escrita literária, compreendida como aquela cuja especificidade maior seria seu traço de ficcionalidade" (p. 7). Assim, embora o conceito de literatura tenha sido construído por uma determinada classe social abastada que ditou um padrão específico de gosto e sensibilidade relativos aos textos, esses textos

\footnotetext{
${ }^{1}$ Neste ponto, faz-se necessário deixar claro o conceito de literatura a que me refiro neste trabalho. Apesar de pertinente, não vou discutir o que é ou o que poderia ser considerado literatura. Como trato do contexto educacional institucionalizado, considero literatura os textos que a escola considera assim, ou seja, textos escritos ficcionais. Quando pertinente, visões diferentes desta serão abordadas. Para maiores discussões sobre o tema, ver Zappone e Wielewicki (2009).
} 
não são o único suporte para o literário. A escola vem, tradicionalmente, calcando sua abordagem da literatura nesses princípios, mas existem outras práticas de letramento literário fora dela. É assim que a audiência de novelas, séries, filmes televisivos, cinema e até a internet, a contação de histórias populares e anedotas, por exemplo, podem ser, segundo Zappone (2007), consideradas práticas de letramento que colocam o indivíduo em relação com a ficcionalidade.

Como segundo ponto, Zappone (2007) aponta para os usos plurais da escrita e busca quais contextos ou espaços sociais em que práticas de letramento literário seriam plurais. Alguns usos sociais seriam adaptações de textos literários para a televisão, teatro ou cinema; por leituras não canônicas, ou leituras não necessariamente calcadas na história de leitura produzida por críticos da academia; leitura de textos não canônicos, como romances cor-de-rosa, best-sellers, etc.; apropriação de textos não produzidos inicialmente como textos ficcionais, mas que funcionam como tal diante de certos públicos, como matérias jornalísticas e depoimentos.

Como terceiro ponto, Zappone (2007) indica as relações de poder que hierarquizam práticas de letramento, já que há formas mais dominantes, mais valorizadas e influentes do que outras. Assim, as práticas desenvolvidas na escola são mais visíveis e valorizadas do que as que acontecem fora das instituições de ensino.

Finalmente, o letramento literário, como as práticas de letramento em geral, são historicamente situados. Assim, indivíduos ou grupos realizam práticas distintas e seus modos de fazer uso da escrita literária e sua leitura também são distintos. Para algumas comunidades, por exemplo, a poesia como é apresentada na escola não faz parte de suas práticas, mas outras formas poéticas poderiam fazer, como canções.

Zappone (2007) conclui que

O conceito de letramento, aplicado ao estudo da literatura mostra-se bastante fértil, pois permite uma compreensão do literário situada para fora dos domínios estritamente ligados ao texto e abre perspectivas para o estudo de variados aspectos relacionados ao modo como se constroem os padrões sociais de letramento literário que levam à efetuação de deferentes práticas em diferentes contextos. Conhecer as práticas de letramento literário presentes na escola bem como as práticas de letramento literários presentes em diferentes âmbitos sociais pode contribuir para que se possa pensar nas relações entre essas duas esferas, escola e vida social, fazendo-as convergir para formação de indivíduos com graus de letramento e letramento literário cada vez maiores (p.9).

No caso do ensino das literaturas estrangeiras, o conceito de letramento literário nos auxilia a pensar sobre a produção da literatura estrangeira e sua circulação e recepção no Brasil. A compreensão sobre o que seria literatura e como deve ser ensinada ainda está calcada nos padrões 
bacharelescos discutidos anteriormente. Apesar das modificações nos cursos de Letras a partir de uma visão de licenciaturas mais focalizada na formação de professores, como também já discutido, a literatura estrangeira ainda está, via de regra, desvinculada de seus contextos de circulação no Brasil. Assim é que não se discute literatura estrangeira nas escolas, embora seja essa característica mais marcante dos textos ficcionais, escritos ou em modos híbridos, que mais as crianças e jovens “consomem" no Brasil.

De uma forma geral, os cursos de Letras preparam professores de literatura brasileira, que vão procurar "incentivar" a leitura de seus alunos de textos ficcionais escritos no Brasil, considerados canônicos pela crítica. A leitura costuma ser desvinculada dos seus contextos de produção, e mais ainda, de recepção. Muitas vezes, por exemplo, alunos de oitava série, na faixa dos treze, quatorze anos de idade, são levados a ler Machado de Assis por sua importância no cenário da literatura nacional, mas totalmente desvinculado dos interesses e maturidade do adolescente de hoje. Algumas tentativas são feitas para estimular essa leitura que a escola julga importante. Estão disponíveis, por exemplo, adaptações para quadrinhos de textos literários canônicos que procuram aproximar, com o aspecto visual, o texto literário da realidade do aluno. Existem as mais diversas produções, e uma posição acerca dos efeitos dessa prática no leitor jovem requer estudo minucioso. Mas, pode-se afirmar que ainda aqui o aspecto visual vem apoiar um texto canônico pré-existente, procurando incentivar que o aluno leia aquilo que a escola julga importante, muitas vezes, na esperança que ele vá, um dia, buscar o original; este sim, detentor de todos os méritos e benefícios para o desenvolvimento artístico e intelectual do indivíduo. A hierarquização do texto literário canônico escrito não permite, muitas vezes, que formas adaptadas sejam vistas como obras em si, com suas próprias especificidades e apelos estéticos.

Paralelamente, professores de língua estrangeira preocupam-se em desenvolver em seus alunos habilidades linguísticas necessárias para seu dia-a-dia, mas receberam também uma formação canônica em termos de textos literários. Mesmo que mais afinados com as abordagens de ensino e aprendizagem de línguas que proponham uma maior articulação com os saberes sociais, esses professores ainda se mostram, no tocante à literatura, presos a uma visão do texto literário como algo de difícil entendimento, que necessita de técnicas especiais de abordagem, e acessível para poucos. Dessa forma, acabam deixando para os professores de literatura a tarefa de ajudarem os alunos a decifrarem os mistérios e as delícias desses textos. Como professores de literatura não trabalham nas escolas com textos estrangeiros, essas produções acabam sendo deixadas de lado. 
Entretanto, quando olhamos as listas de livros mais vendidos, percebemos que o seu topo é sempre ocupado por publicações estrangeiras. Todos os anos, a indústria cinematográfica lança filmes dos mais diversos tipos, grande número deles baseados em obras literárias estrangeiras. Séries de TV são consumidas avidamente, textos literários circulam no meio virtual, inicialmente produzidos nele, ou adaptados de outros meios. Como esses meios de circulação não são valorizados pela escola, repete-se indefinidamente que os jovens não leem. A escola encontra-se, assim, totalmente desvinculada das formas ficcionais acessadas pelos jovens. Os resultados apontados pelos integrantes do Projeto de Pesquisa Institucional "Multimodalidade, língua inglesa e educação literária: novas tecnologias e a formação da identidade leitora", desenvolvido desde 2009 na Universidade Estadual de Maringá, apontam para a circulação da literatura estrangeira no Brasil em contextos não escolares, através de diferentes meios, e sua dissociação da escola. Os resultados parciais das pesquisas já demonstram que podemos afirmar que os jovens têm acesso a narrativas, à ficcionalidade, em grande parte oriundas das culturas estrangeiras e interagem com essas formas, mas não têm vínculos com práticas nas escolas. Como são consideradas menores pelo sistema educacional vigente, não se considera leitura literária práticas que digam respeito a narrativas mais visuais, como o cinema e a TV, ou estórias em quadrinhos, ou mesmo jogos eletrônicos. Tampouco é considerada válida pela escola a interação com o texto literário através de fanfics, sites onde os fãs de livros, filmes, graphic novels ou mesmo mangás podem conversar com seus textos preferidos e inserir seus próprios textos, complementando, refazendo as narrativas (Zappone 2008) ${ }^{2}$. Uma breve consulta ao site www. fanfiction.com.br, por exemplo, nos dá algumas informações importantes. Página brasileira, informa já na sua apresentação suas características básicas:

\footnotetext{
Qual a finalidade deste site e como funciona?

Todas as histórias postadas no site são ficções criadas por fãs - fanfiction - de animes, seriados, filmes, livros, bandas e muito mais. Este site foi criado com o intuito de divulgar as séries originais, reunir seus fãs e proporcionar momentos de lazer através da leitura, assim como incentivar as pessoas a trabalharem seu lado criativo escrevendo suas próprias histórias. Você não paga nada para ler ou postar no site, o uso é gratuito!
}

A fanfic apresenta-se, de início, como uma comunidade virtual em que é possível interagir com obras ficcionais de forma espontânea, já que não induzida por uma instituição formalizada. As escolhas, aqui, de interagir com a página ou não, baseiam-se simplesmente em opções de lazer livres. Entretanto, uma vez feita a escolha de participar do grupo, existem regras rígidas que devem ser

\footnotetext{
${ }^{2}$ Elaine Cristina Amorin defendeu dissertação de mestrado com o título "Leitores e leituras de Harry Potter: a recepção da série no meio virtual”, pelo Programa de Pós-Graduação em Letras da Universidade Estadual de Maringá em 2009.
} 
seguidas. Os textos podem ser aceitos ou não, de acordo com tais regras, explicitadas na página. Uma vez aceitos, os outros participantes podem fazer comentários, o que vai criar uma audiência que pode gostar, ou não, do que leu, e emitir opinião. Há no site, ainda, uma janela denominada Português, com os dizeres "dicas para escrever bem" que procura orientar os usuários sobre os padrões linguísticos aceitos. Tudo o que a escola gostaria de fazer. Tem-se aqui a leitura, a escrita criativa e a escrita crítica, para uma audiência jovem verdadeiramente interessada. Informações sobre o que essa audiência lê também podem ser obtidas através de uma observação das categorias presentes no site. A janela Categorias apresenta as seguintes possibilidades: animes, bandas, cartoons, filmes, jogos, livros, originais, personalidades, poesias, quadrinhos e seriados. Na categoria livros, organizada em ordem alfabética, a saga Crepúsculo é campeã de contribuições: 10.453, seguida de Harry Potter, com 6.047; Percy Jackson e os Olimpianos, com 2.336. Crônicas de Nárnia e Senhor dos Áneis, com números mais modestos, também merecem ser citados, com 119 e 49 contribuições, respectivamente.

Pode-se argumentar que tais materiais estariam acessíveis apenas a uma elite leitora, capaz de acessar a internet e interagir nesse meio. A atividade pressupõe, também, acesso a livros e filmes. Pode ser. Mas não se pode ignorar as fanfics como um meio válido de articulação com a leitura e escrita, cada vez mais disponível, inclusive com o acesso à internet propiciado por programas do governo para escolas e a organização de bibliotecas públicas.

Considerações à parte merecem as séries de livros que inspiram filmes, com todo um entorno de produções que incluem revistas, álbuns de figuras, jogos eletrônicos, parques temáticos, bonequinhos vendidos com lanches, temas para festas de aniversário, roupas, materiais escolares e mais uma infinidade de produtos comercializados nas mais diversas faixas de consumo. Os atores que personificam os personagens no cinema acabam, eles também, veiculando determinados modos de vida que são imitados pelos jovens na ânsia de tornar real a fantasia vivenciada nos diversos meios. Os personagens dessas séries, como Harry Potter, Senhor do Anéis e Crepúsculo, para citar as mais famosas, inspiram comportamentos e alavancam uma indústria bastante consciente de sua potencialidade. Só a escola, parece, ainda não percebeu isso. E, quando permite que esse mundo adentre seus muros, o faz na esperança de que os jovens, com o tempo, reconheçam a posição culturalmente inferior de tais produções e desenvolvam, na hora certa, gosto artístico e maturidade intelectual mais apurados para "separar o joio do trigo" e fazerem, oportunamente, as escolhas adequadas.

Adotando-se uma perspectiva do letramento crítico, então, fica evidente que seria interessante a escola acrescentar em seu currículo as formas ficcionais que circulam entre os jovens, bem como 
preparar os professores, em sua formação básica e continuada, para trabalharem com esse material, de rico potencial significativo, de forma crítica. Coloca-se aqui, entretanto, outra questão: será que essa "literatura" que circula fora do âmbito escolar, e é acessada aí, pode ser incorporada pela escola sem o risco de perder seu sabor para os jovens leitores?

\section{AVALIAÇÃo}

Um dos aspectos basilares da forma como a educação institucional é estruturada, de forma geral, é a avaliação. Calcada em uma necessidade de mesurar conhecimentos, a aprovação de uma etapa para a outra pressupõem a comprovação de que os alunos assimilaram informações específicas, determinadas como fundamentais para uma determinada etapa. Podemos desdobrar a questão da avaliação da literatura estrangeira nas escolas, caso possamos reconhecê-la como parte integrante de currículos de ensino, em questões de avaliação gerais, de avaliação da literatura, como concebida pela escola, e questões de avaliação da língua estrangeira.

A avaliação incomoda muitos pesquisadores preocupados com os contextos sociais da produção de conhecimentos. Lankshear e Knobel (2009) escrevem sobre o sistema de testes da educação ocidental, especificamente da Inglaterra. Para os autores, a educação britânica encontra-se sedimentada em um currículo nacional ou estadual e sua aferição pela escola e pelo professor. A base regular dessa aferição são testes nivelados e critérios mensuráveis, levando a abordagens educacionais que priorizam o desempenho em tais testes. Não se considera, entretanto, que os resultados dos testes possa ser manipulado, desviando a atenção para fatos mais amplos do que aqueles focalizados. Para testes nacionais, por exemplo, professores chegam a pedir, segundo os autores, que alunos considerados mais fracos não compareçam no dia do teste, não contribuindo para a diminuição do nível considerado como ideal para os resultados pretendidos. Lankshear e Knobel (2009) questionam, em vista desse panorama, qual a razão de ser testar tanto, e buscam a reposta no conceito de performatividade de Lyotard. O conhecimento, presentemente, é produzido para ser vendido e consumido de forma a ser valorizado em uma nova produção, assim, a educação é vista como performatividade, seguindo o princípio de otimizar o desempenho de instituições sociais, como escolas, segundo critérios de eficiência: a educação passa a ser uma sub-setor da economia. Para os autores, o problema das escolas encontra-se na natureza do aprendizado curricular, visto separadamente da participação em versões "maduras" de práticas sociais, ou seja, o aprendizado na escola é desconectado do que se faz no mundo "real". Essa visão é totalmente corroborada pelas 
críticas já discutidas aqui acerca do papel da escola nos diversos letramentos, em especial do letramento literário. Também aqui, no Brasil, os testes visam aferir conhecimentos estanques, desconectados das práticas sociais significativas para os indivíduos e não medem, de maneira alguma, as possibilidades de articulação desses indivíduos com os diversos discursos que os informam.

Em termos da avaliação dos saberes literários, a princípio, partimos do pressuposto que as informações ensinadas a avaliadas pela escola são historicamente situadas, determinadas pelos saberes que uma parcela da população acredita que deva ser valorizado. Assim, o conhecimento literário acaba sendo avaliado por modelos epistemológicos positivistas, como o reconhecimento das partes constitutivas daquilo que se considera literatura (personagem, enredo, espaço, tempo), reconhecimento da inserção do cânone em períodos históricos determinados cronologicamente (características dos períodos romântico, realista, modernista, por exemplo) e reconhecimento das leituras chanceladas pela crítica literária canônica. Nesse contexto, as formas narrativas ficcionais discutidas anteriormente não têm espaço. Seria incongruente, também, tentar trazer Harry Potter ou Crepúsculo para os padrões de estudos literários que a escola vem desenvolvendo e testando. O prazer que os jovens obtêm com esse tipo de leitura seria destruído com uma lista de personagens planos ou redondos, ou leituras acadêmicas formalizadas.

A avaliação do ensino da língua estrangeira, por sua vez, preocupa Duboc (2007) que se debruça sobre a avaliação em uma base dos letramentos críticos. Para a autora, os problemas da avaliação nesse contexto giram em torno de sua significação como sinônima de mensuração, na ênfase à avaliação de conteúdos objetivos, estáveis e memorizáveis e em provas escritas. Assim, para a escola, importa o que os alunos podem produzir de forma quantificável, facilmente visualizada através de conteúdos fixos e classificáveis em padrões de certo e errado. Mais uma vez, os conteúdos ensinados e cobrados na escola estão desarticulados dos fazeres sociais dos indivíduos. Aqui, mais uma vez, uma abordagem de literatura como sugerida pelo conceito de letramento literário, não cabe. Para Duboc (2007), o problema da escola está em seus critérios avaliativos, sendo necessária uma nova base epistemológica de avaliação.

Pensando em bases epistemológicas, tanto de avaliação quanto do ensino mesmo, sugeri em outra oportunidade (Wielewicki 2010) que a própria crença na necessidade de avaliação está calcada em uma base epistemológica que visa uma aprovação de algo que se considera superior. Recorrendo a Bhabha, e conceitos de hibridismo e tradução cultural, pode-se propor que o novo entra no mundo através de uma atitude herética, desafiando padrões pré-estabelecidos. Derrida, retomando Benjamin, 
lembra a situação paradoxal da dívida do tradutor, já que a tradução é vista ao mesmo tempo como uma necessidade e uma impossibilidade. A palavra geradora, passível de tradução, processo de garante sua sobrevida, não pode, ao mesmo tempo, ser traduzida completamente. Sua ressignificação será sempre uma heresia, posto que fere sua autoridade original. Da mesma forma, os sentidos novos serão sempre heréticos, pois ao mesmo tempo em que tocam, mesmo tangencialmente, como nos lembram Benjamim e Derrida, a palavra geradora, não mais contituem essa palavra. O desejo de testagem pode ser visto, assim, como uma busca pela vida surgida previamente, como uma aprovação dessa palavra, tida como maior, mais original, primeira, mais completa. Dessa forma, a própria necessidade da testagem insere-se em uma epistemologia que hierarquiza, classifica, seleciona, enfim, julga.

\section{CONSIDERAÇÕES FINAIS}

A conclusão a que chego em relação à literatura estrangeira e ao ensino escolarizado é de que as teorias de letramento crítico, e o conceito de letramento literário aqui exposto podem ser uma caminho para uma abordagem de textos ditos literários em escolas válida em termos de sua contribuição para uma melhor articulação do ensino escolarizado com os contextos reais de produção, circulação e recepção, ou consumo, desses textos. Entretanto, quando nos dedicamos aos moldes nos quais a escola está formatada, e entre eles a avaliação, questiono como devemos trazer essas formas não convencionais para a escola. Parece-me que elas já sobrevivem bem fora dos esquemas rígidos educacionais, e querer abarcá-las por esses esquemas pode acabar empalhando a borboleta que voa livre. Ela sabe de suas possibilidades e limitações, seu plano de vôo não precisa ser traçado por técnicos em aeronáutica. A escola pode e deve contribuir para o posicionamento crítico dos cidadãos, mas não consegue delimitar todas as possibilidades de produção de sentidos, e algumas delas, talvez, seja melhor deixar voar livres.

\section{REFERÊNCIAS}

CALVO, L.C.S.; FREITAS, M.A. Prática como componente curricular e sua implementação em sala de aula na visão de formadores de um curso de Letras. Acta Scientiarum, Language and Culture. Maringá, v.33, n.2, 2011, pp. 315-327. 
DUBOC, A.P.M. A avaliação da aprendizagem de língua inglesa segundo as novas teorias do letramento. Fragmentos. Florianópolis, n. 33, /jul-dez/2007. pp. 263-277.

KLEIMAN, A.B. Introdução: O que é letramento? Modelos de letramento e as práticas de alfabetização na escola. In: - - -. (org.) Os significados do letramento. São Paulo: Mercado de Letras, 2004.

LANKSHEAR, C.; KNOBEL, M. More than words: Chris Searle's approach to critical literacy as cultural action. Institute of Race Relations, vol. 51(2), 2009, pp. 59-78.

ROJO, R. Letramento escolar, oralidade e escrita em sala de aula: diferentes modalidades ou gêneros de discurso? In: SIGNORINI, I. (org.) Investigando a relação oral/escrito e as teorias do letramento. Campinas: Mercado de Letras, 2006. pp. 51-74.

WIELEWICKI, V.H.G. Hibridismos, tradução cultural e linguagens: implicações para o ensino e a avaliação. Revista Letras e Letras. Uberlândia-MG, v. 26, n.2, jul.dez. 2010, pp.443-453.

ZAPPONE, M.H.Y. Modelos de letramento literário e ensino da literatura: problemas e perspectivas. Teoria e Prática da Educação, v. 03, 2007, pp. 47-62.

ZAPPONE, M.H.Y. ; WIELEWICKI, V.H.G. Afinal, o que é literatura? In.: BONNICI, T.; ZOLIN, L.O. (org.) Teoria Literária. Abordagens históricas e tendências contemporâneas. 3.ed. Maringá: EDUEM, 2009, pp. 19-30.

Site da Internet

NYAH! Fanfiction. http://www.fanfiction.com.br/ acessado em 02/10/2011. 